\title{
Petroclival Meningiomas: Factors Determining the Choice of Approach
}

\author{
Gustavo Rassier Isolan ${ }^{1,2}$ Sâmia Yasin Wayhs ${ }^{3}$ Guilherme Alves Lepski ${ }^{4,5}$ Leandro Infantini Dini ${ }^{2}$ \\ Joel Lavinsky 6,7
}

${ }^{1}$ Graduate Program in Medicine: Surgical Sciences, Universidade Federal do Rio Grande do Sul (UFRGS); Neurotology and Acoustic Neuroma Center (CNNA); Clínica Lavinsky; Hospital Moinhos de Vento - Porto Alegre, Rio Grande do Sul, Brazil

2 The Advanced Neurology and Neurosurgery Research Center (CEANNE), Porto Alegre, Rio Grande do Sul, Brazil

3 Graduate Program in Medicine: Surgical Sciences, UFRGS, Porto

Alegre, Rio Grande do Sul, Brazil

${ }^{4}$ Department of Neurology, Division of Neurosurgery, Universidade de São Paulo (USP), São Paulo, São Paulo, Brazil

${ }^{5}$ Department of Neurosurgery, Eberhard Karls University,

Tübingen, Germany

${ }^{6}$ Hospital Moinhos de Vento, Porto Alegre, Rio Grande do Sul, Brazil

${ }^{7}$ CNNA; Clínica Lavinsky, Porto Alegre, Rio Grande do Sul, Brazil
Address for correspondence Gustavo Rassier Isolan, MD, PhD, Graduate Program in Medicine: Surgical Sciences, Universidade Federal do Rio Grande do Sul (UFRGS); The Advanced Neurology and Neurosurgery Research Center (CEANNE), Rua Ramiro Barcelos, 2400, $2^{\circ}$ andar, 90035-003 - Porto Alegre, RS, Brazil (e-mail: ppgcirur@ufrgs.br).

J Neurol Surg B 2018;79:367-378.

\begin{abstract}
Keywords

- brain tumor

- clivus

- meningioma

- petroclival

- skull base

Objectives To review a surgical series of petroclival meningiomas and the factors considered in the choice of approach.

Design Retrospective review.

Setting The study was conducted in a university hospital in southern Brazil.

Participants Twenty-two patients with petroclival meningioma originating from the upper two-thirds of the clivus medial to the fifth cranial nerve.

Main Outcome Measures Gross-total resection, mortality, major morbidity, new cranial nerve deficits and tumor progression or recurrence.

Results Retrosigmoid approach was used in tumors $<3 \mathrm{~cm}$ and in those at or below the internal auditory meatus. Posterior petrosectomy was performed for tumors extending into the middle fossa. Gross-total resection was performed in 11 patients (50\%). The mean follow-up time was 32 months (6-75 months). There were four cases of tumor progression or recurrence, which were treated with radiosurgery.

Conclusions Resection of petroclival meningiomas remains challenging. In most cases, the retrosigmoid approach was sufficient, without affecting the degree of tumor resection. Petrosal approaches were reserved for patients with tumor extension into the middle fossa.
\end{abstract}

\section{Introduction}

Petroclival meningiomas remain one of the most challenging surgical lesions of the skull base. Over the past three decades, advances in microsurgical techniques, new operating microscopes, ultrasonic aspirators, intraoperative neuromonitoring, and advances in intensive care and microsurgical anatomy have led to better outcomes than has the natural history of the disease, with acceptable morbidity. ${ }^{1-16}$
DOI https://doi.org/ 10.1055/s-0037-1608654. ISSN 2193-6331.
June 22, 2017

accepted after revision

September 30, 2017

published online

December 11, 2017 (c) 2018 Georg Thieme Verlag KC Stuttgart - New York 
Posterior fossa meningiomas can be located at different sites in relation to the clivus. Conceptually, petroclival meningiomas are located medial to the fifth cranial nerve $(\mathrm{CN} \mathrm{V})^{1,15,16}$ Petrous, tentorial, cavernous sinus, and midclival meningiomas and meningiomas originating from the anterior border of the foramen magnum are not considered petroclival meningiomas, and the decision on which approach to use depends greatly on this factor. Petroclival meningiomas frequently displace the brainstem and basilar artery posteriorly and to the contralateral side. They may also displace or involve CN III, IV, and V, displace CN VII laterally and CN VI medially, and extend into the internal auditory meatus, jugular foramen, Meckel's cave, Dorello's canal, and the ipsilateral cavernous sinus. $^{13,15}$

Because of the rarity of these tumors and the different management philosophies in skull base approaches, there is currently no high-quality, high-level decision based on randomized controlled trials establishing the superiority of one surgical approach over another. The trans-temporal and fronto-orbito-zygomatic approaches can reduce the operative distance to the tumor and give a wider exposition of the tumor and its relationship with the CNs. However, the retrosigmoid approach results in fewer approach-related complications and is less time consuming. Some authors state that the main reason for subtotal resection is the lack of a dissection plane or infiltration into $\mathrm{CNs}$, brainstem, or major vessels, ${ }^{17,18}$ regardless of the approach.

The aim of this study was to review a series of petroclival meningiomas and assess the factors used to determine the choice of surgical approach.

\section{Methods}

Of a series of 53 patients treated for posterior fossa meningiomas by the first author (Gustavo Rassier Isolan) between 2007 and 2014, 32 had petroclival meningiomas. Of these, 22 met the criteria for "true" petroclival meningioma: those originating from the upper two-thirds of the clivus medial to the $\mathrm{CN} \mathrm{V}{ }^{15}$ Their medical records, imaging studies, and pathology reports were reviewed. Ten patients were not operated on: two refused surgery due to advanced age or comorbidities; four were asymptomatic with a predominantly cavernous pattern; and four showed no tumor growth on serial magnetic resonance imaging (MRI). Because these 10 patients had no clinical visual loss or extraocular muscle impairment, they were primarily referred for upfront radiosurgery or radiotherapy. Gross-total resection (GTR) was defined as Simpson grade I, II, and III resection ${ }^{19}$ ( - Table $\mathbf{1}$ ), confirmed by postoperative gadolinium-enhanced MRI. The study was approved by the Research Ethics Committee at Hospital de Clínicas de Porto Alegre.

\section{Results}

\section{Clinical Characteristics}

Twenty-two patients underwent resection of petroclival meningiomas over a 7-year period; there were 18 women, and the mean age was 52.4 years (range $35-82$ years). Headache was the most common presenting symptom, observed
Table 1 Simpson grading system for meningiomas according to the extent of resection

\begin{tabular}{|l|l|}
\hline Grade & Definition \\
\hline I & $\begin{array}{l}\text { Macroscopically complete removal with } \\
\text { excision of dural attachment and } \\
\text { abnormal bone }\end{array}$ \\
\hline II & $\begin{array}{l}\text { Macroscopically complete removal with } \\
\text { endothermy coagulation (Bovie or laser) } \\
\text { of dural attachment }\end{array}$ \\
\hline III & $\begin{array}{l}\text { Macroscopically complete removal } \\
\text { without resection or coagulation of } \\
\text { extradural extensions }\end{array}$ \\
\hline IV & $\begin{array}{l}\text { Partial removal leaving intradural tumor } \\
\text { in situ }\end{array}$ \\
\hline V & $\begin{array}{l}\text { Simple decompression with or without } \\
\text { biopsy }\end{array}$ \\
\hline
\end{tabular}

in 18 patients, followed by hearing loss $(n=12)$, facial numbness $(n=5)$, ataxia $(n=3)$, progressive hemiparesis $(n=2)$, and facial weakness $(n=2)$. Trigeminal neuropathic pain refractory to conventional medical therapy was the main symptom in two patients. Difficulty swallowing due to lower $\mathrm{CN}$ deficits was present in three patients. Four patients had papilledema due to hydrocephalus. One older patient had severe visual loss, which justified the surgical approach. MRI findings are shown in -Table 2.

\section{Pathology}

Except for one Grade 2 meningioma with brainstem edema and one Grade 3 meningioma, all other tumors in this series were classified as World Health Organization (WHO) Grade 1.

Table 2 Magnetic resonance imaging findings

\begin{tabular}{|l|l|}
\hline Parameter & No. of cases \\
\hline Brainstem compression & 11 \\
\hline Tumor size (in cm) & \\
\hline$>6$ & 11 \\
\hline $3-6$ & 3 \\
\hline$<3$ & 8 \\
\hline Extension & \\
\hline Into CS & 9 \\
\hline Into IAM & 7 \\
\hline Into JF & 3 \\
\hline BA displacement & 8 \\
\hline BA encasement & 3 \\
\hline Plane on T2-weighted images & 15 \\
\hline Brainstem edema & 3 \\
\hline $\begin{array}{l}\text { Supratentorial ventricular } \\
\text { dilatation with ICH signals }\end{array}$ & 4 \\
\hline
\end{tabular}

Abbreviations: BA, basilar artery; CS, cavernous sinus; IAM, internal auditory meatus; ICH, intracranial hypertension; JF, jugular foramen. 


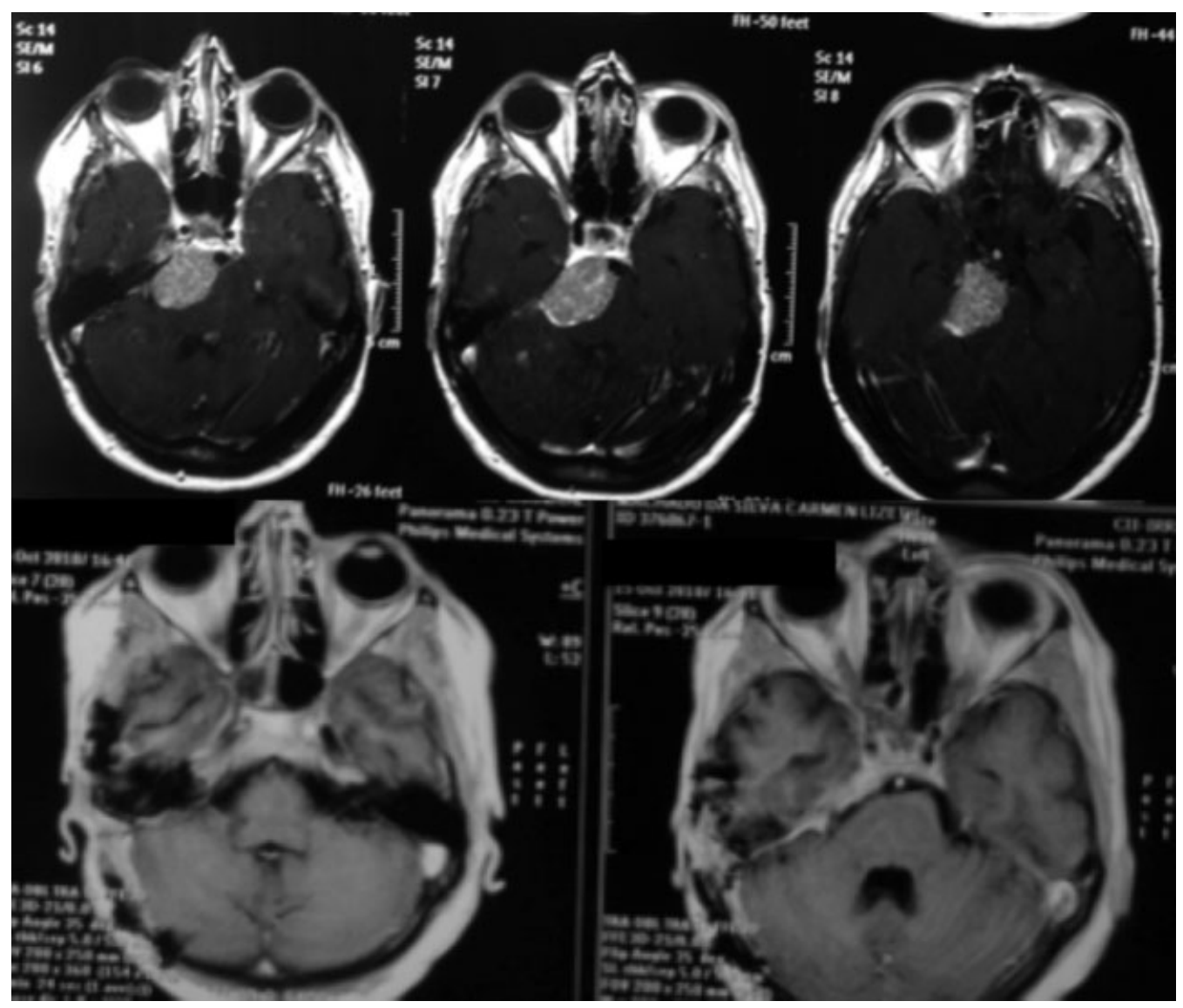

Fig. 1 Petroclival meningioma of the middle third of the clivus in a patient with preserved hearing. A posterior petrosectomy was performed with complete tumor resection without postoperative deficits.

\begin{abstract}
Approaches
Early in the series, lateral skull base approaches (petrosal approaches) were performed in patients, regardless of tumor size (-Fig. 1). At that time, posterior petrosectomy was performed in six patients (-Figs. 2, 3, and 4), and total petrosectomy-double petrosal-was used in two patients. After 2011, the retrosigmoid approach was used in tumors $<3 \mathrm{~cm}$ and in those at or below the internal auditory meatus (-Fig. 5). The posterior petrosal approach was the choice in tumors extending into the middle fossa, as it allows simultaneous exposure of the middle and posterior fossa. In these cases, magnetic resonance angiography was performed to identify the insertion of the vein of Labbé. If the vein of Labbé drained into the superior petrosal sinus or the patient had a high jugular bulb, the lateral skull base approaches were not considered. ${ }^{20}$-Table 3 shows the approaches used in this series and their results. The fronto-orbito-zygomatic approach was reserved for a specific case (-Fig. 4).

One patient had a small sphenopetroclival meningioma with invasion of the sphenoid sinus causing rhinorrhea. In this case, extended endoscopic endonasal approach was used for partial resection of the lesion inside the sphenoid sinus. The fistula was treated with a pedicled nasoseptal flap with postoperative resolution of the cerebrospinal fluid (CSF) leak, and the patient was later referred for radiosurgery. Over 1 year of follow-up, MRI showed no evidence of tumor growth. ${ }^{21}$
\end{abstract}

GTR was achieved in 11 patients (50\%). The reasons for incomplete resection were as follows: tumor adherence to the brainstem in two patients; adherence to major blood vessels in two patients; and venous infarction of the temporal lobe in two patients, which required interruption of the procedure. In three patients, some minor residual tumor was deliberately left in the region of the cavernous sinus. In two cases of sphenopetroclival meningioma, the goal was to perform a partial resection for optic nerve decompression. These five patients with subtotal resection were supplemented with radiosurgery. In addition, tumor progression was observed in two patients with residual tumor, and both underwent radiosurgery. The remaining patients with small residual tumor are currently being followed.

In this initial series, we have not changed our impression regarding GTR between intraoperative evaluation and postoperative MRI. It should be taken into account that we considered Simpson I, II, and even III as GTR, as in most other series reported in the literature. Using this concept, we already know intraoperatively whether GTR was achieved. There is a risk of failing to perceive part of the tumor in the middle fossa if a retrosigmoid approach is used. To avoid this, we performed a posterior petrosal approach that provided a full view of the middle fossa extension. In cases of cavernous sinus invasion, we also anticipated that part of the tumor had to be considered a "leave-me-alone lesion," except in cases with visual impairment caused by this component. 


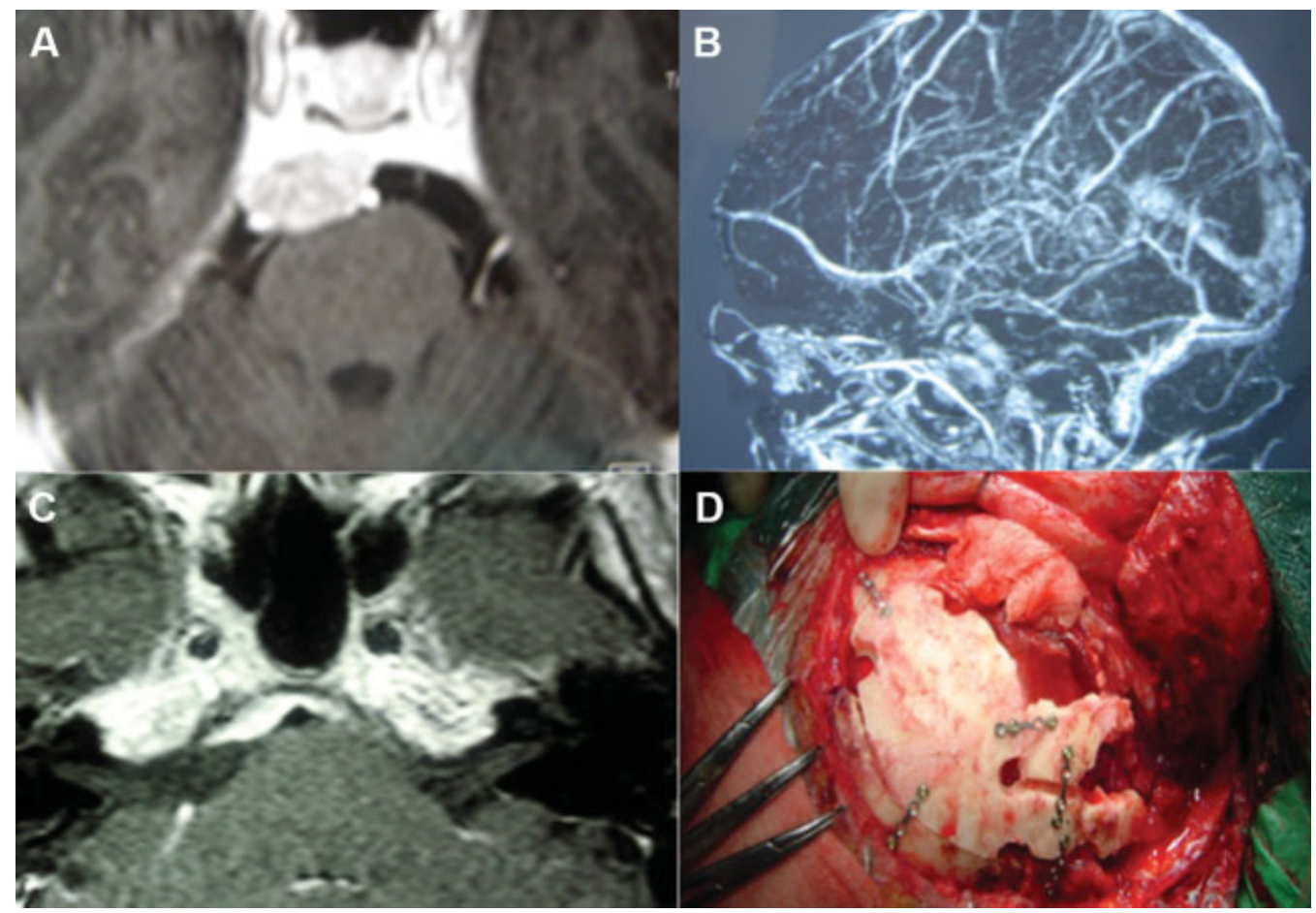

Fig. 2 A 43-year-old patient with an asymptomatic petroclival meningioma involving the upper and middle clivus. A posterior petrosectomy was performed without labyrinthectomy due to preoperative hearing preservation. (A) Gadolinium-enhanced T1-weighted MRI showing the tumor. (B) Venous MR angiography showing posterior insertion of the vein of Labbé in the superior petrosal sinus, not contraindicating complete petrosal approach. (C) Gadolinium-enhanced T1-weighted MRI 3 months after surgery showing Simpson III tumor resection, as expected through intraoperative view. (D) Mastoid reconstruction. The patient had no postoperative deficits and showed no recurrence 6 years after surgery. MR, magnetic resonance; MRI, magnetic resonance imaging.

\section{Morbidity and Mortality}

- Tables 3 and 4 show surgically induced CN deficits, improvement in previous deficits, and the Simpson grade of resection. There were two perioperative deaths in this series: an older patient, who was operated on due to severe visual loss, died 3 weeks after surgery due to complications of pneumonia and sepsis; and another patient died due to extensive malignant cerebral venous infarction after complete resection of sphenopetroclival tumor 15 days after surgery.

Early in the series, two patients had a stroke resulting in major neurological deficits: one left temporal lobe venous infarction and one brainstem infarction. The former case had a large petroclival meningioma, presenting tetraparesis and paralysis of right CN V to XII, and developed hemiplegia in the postoperative period and pneumonia. In the latter case, the venous infarction was probably due to brain retraction during anterior petrosectomy. This patient underwent emergency decompressive craniectomy 24 hours after surgery, but his aphasia and right hemiplegia persisted. Another patient developed posterior fossa hypertension after a suboccipital retrosigmoid approach, with persistent hemiparesis even after emergency decompressive surgery. This patient had pneumonia and critical illness polyneuromyopathy. There was no specific description between these ischemic events and tumor consistency as measured by T2 signal, presence of CSF cleft between tumor and brainstem on MRI, or MRI evidence of brainstem edema.
New postoperative cranial neuropathies occurred in seven patients. The $\mathrm{CN}$ dysfunctions observed after surgery were facial numbness ( $n=2)$, facial weakness $(n=5)$, abducens nerve palsy $(n=2)$, trochlear nerve palsy $(n=3)$, and oculomotor nerve palsy ( $n=1)$; of these, four were transient. Three patients had permanent deficits 6 months after surgery. Cross-facial nerve grafting for facial nerve reanimation and muscle transposition were performed in three patients by the plastic surgery team. One patient had persistent CN VI palsy and was referred to a neuro-ophthalmologist. Patients with CN IV palsy reported diplopia; however, after 6 months, symptoms were mild, and none of the patients needed further treatment.

Four patients had hydrocephalus before surgery and underwent ventriculoperitoneal shunt placement. One patient developed hydrocephalus after surgery. CSF leaks (rhinorrhea) occurred in two patients after a petrosal approach and were treated with lumbar drainage. These two patients also required ventriculoperitoneal shunt placement. Three patients developed meningitis, which was successfully treated. Two patients with refractory trigeminal neuropathic pain improved their pain scores in the immediate postoperative period due to decompression of the trigeminal nerve (-Figs. 6 and 7). One patient with a large calcified petroclival meningioma and swallowing deficit underwent partial tumor resection, and his deficit improved postoperatively. He had been followed up for 5 years, and no new symptoms or tumor growth occurred. Another patient who 


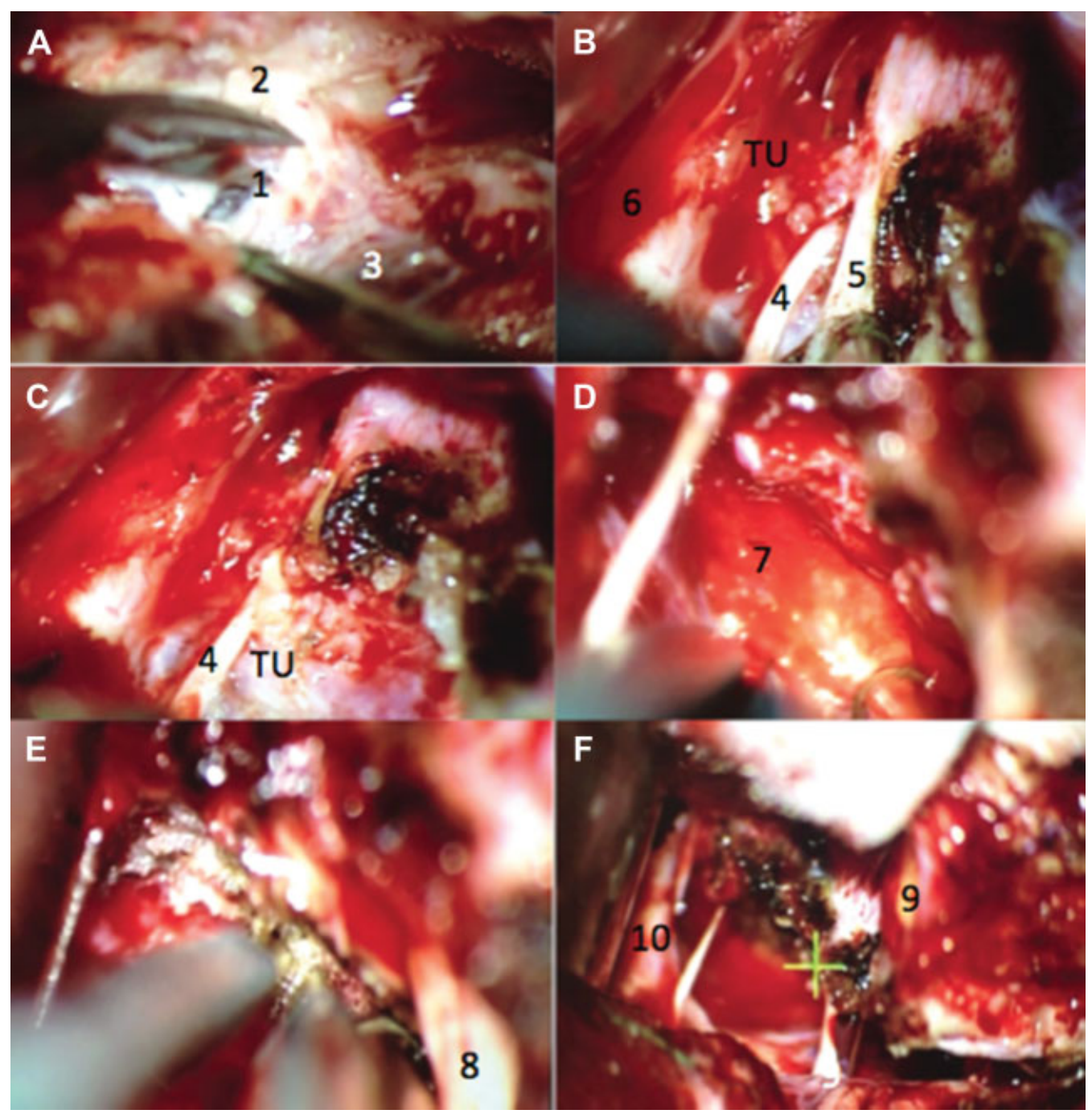

Fig. 3 Previous case. (A) Presigmoid dural opening. (B) Coagulation of the tentorium and identification of the trochlear nerve before cutting the tentorium. (C) Tentorium free edge was released and reflected, noting the relationship of the tumor with the trochlear nerve. (D) Clivus insertion after tumor resection. (E) Clivus dural coagulation after tumor resection. (F) Cranial nerve preservation within the surgical field after tumor resection. 1. Presigmoid dura mater; 2 . mastoid portion of the temporal bone; 3 . sigmoid sinus; 4 . trochlear nerve; 5 . tentorial notch; 6. temporal lobe; 7. clivus; 8. trigeminal nerve; 9. superior petrosal vein; and 10. basilar artery. TU. Tumor.

also had a huge petroclival meningioma had progressive hemiparesis due to brainstem compression. This patient had facial and lower $\mathrm{CN}$ palsies due to two attempts of resection in another service. The patient's hemiparesis improved postoperatively.

\section{Tumor Recurrence}

Adequate radiographic follow-up (minimum of 6 months) was available for 14 patients, and recurrence rates were calculated based on the follow-up of these patients. The mean follow-up time was 32 months (range 6-75 months). In three of 14 patients followed up for $>6$ months, tumor progression or recurrence was observed. In two patients, in whom the cavernous sinus component of the sphenopetroclival meningioma was left intact, this component started to grow toward the incisural space as noted in postoperative MRIs 7 and 11 months after surgery, respec- tively. One patient was referred for radiosurgical treatment, and the other was being followed up due to relatively slow growth. Another patient presented a small tumor recurrence at the clivus. All three of these patients were asymptomatic.

\section{Discussion}

The slow-growing pattern of petroclival meningiomas is usually associated with the onset of symptoms only after reaching a large size. Van Havenberg et $\mathrm{al}^{22}$ investigated 21 patients with petroclival meningioma treated conservatively, with a minimum follow-up of 4 years. They reported tumor growth in $76 \%$ of cases and clinical deterioration in $63 \%$. Bricolo et $\mathrm{al}^{2}$ reported that an average of 2.5 to 4.5 years elapse between the onset of symptoms and confirmation of diagnosis, which delays treatment. Jung et $\mathrm{al}^{23}$ reported a 


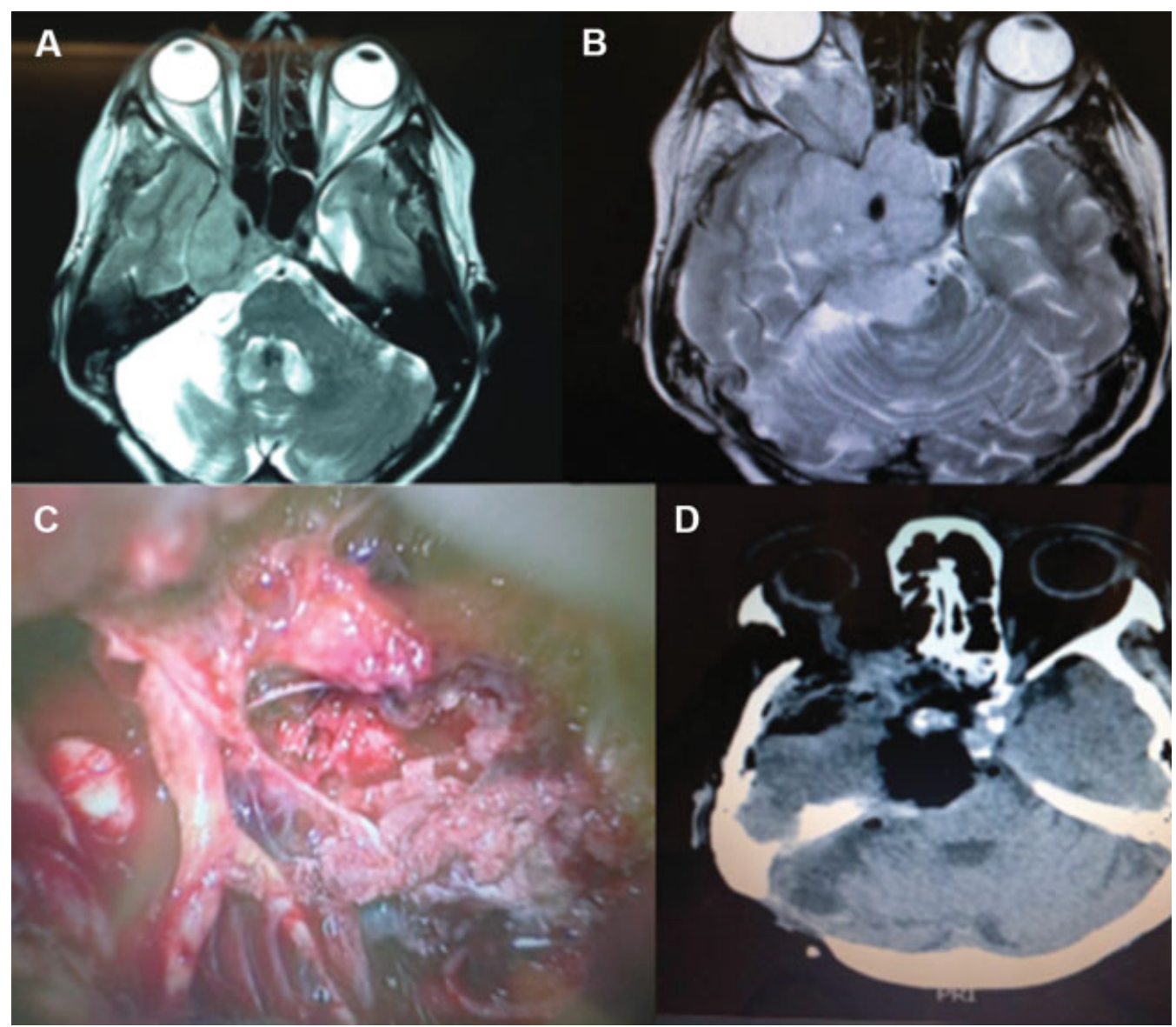

Fig. 4 Patient with prior posterior fossa tumor resection and adjuvant whole-brain radiotherapy 20 years earlier. Neurological examination showed paralysis of all cranial nerves related to the cavernous sinus and right amaurosis, ataxia. The new MRI revealed an enlargement of the tumor extending into the upper clivus, orbit, infratemporal, and pterygopalatine fossae (A and B). A combined approach was used (fronto-orbitozygomatic craniotomy with previous petrosectomy), with complete tumor resection and wide reconstruction using fat and a temporalis muscle flap (C). The siphon and petrous segment of the internal carotid artery were skeletonized after resection of the petrous apex in the Mullan's triangle and Kawase's triangle to resect tumor extensions into the pterygopalatine and infratemporal fossae, respectively (D). The patient died due to a postoperative hemispheric venous infarction and pulmonary sepsis 3 weeks after surgery. The pathological study demonstrated anaplastic meningioma. MRI, magnetic resonance imaging.

series of 38 patients who had subtotal resection. Linear growth was $0.37 \mathrm{~cm} /$ year, and volume increased by $4.94 \mathrm{~cm}^{3} /$ year. However, $60 \%$ of patients showed no signs of disease progression. Watchful waiting may be an option for patients who are poor candidates for surgery, elderly patients, patients with very small asymptomatic lesions, or when the patient is unwilling to undergo surgical treatment. In these cases, MRI may be repeated every 6 months or when new symptoms arise.

Most petroclival meningiomas are benign lesions. Complete resection is generally the only possible curative treatment, but it is often impossible due to invasion of the cavernous sinus, CNs, vessels, and pia mater. The size, consistency, and biological behavior of the tumor are other factors limiting the extent of resection. The best surgical outcomes are usually achieved with small tumors (up to $3 \mathrm{~cm}$ in diameter). ${ }^{9,24}$ They may carry the greatest potential for cure, possibly with the least morbidity. ${ }^{24}$ Nevertheless, these patients are also the best candidates for radiosurgery. ${ }^{10}$
Subtotal resection with or without adjuvant therapy is usually performed when there is invasion of the cavernous sinus. Little et $\mathrm{al}^{7}$ found that subtotal resection in patients with adherent or fibrous tumors significantly reduced the rate of postoperative neurological deficits without a significant increase in the rate of tumor recurrence. Nanda et $\mathrm{al}^{13}$, in a series of 50 patients with petroclival meningioma, achieved GTR in $28 \%$ of cases, with good functional outcome in $92 \%$; their primary surgical goal was to achieve maximal tumor resection while maintaining or improving function. They suggested that residual or recurrent tumors might be treated with stereotactic radiosurgery (SRS). In the present series, involvement of the cavernous sinus in asymptomatic patients has led to the choice of follow-up and adjuvant treatment with radiosurgery in case of tumor recurrence.

Fractionated stereotactic radiotherapy and radiosurgery may be indicated as first-line or adjuvant therapy for skull base meningiomas and are considered to provide good outcomes in terms of tumor control and preservation of 


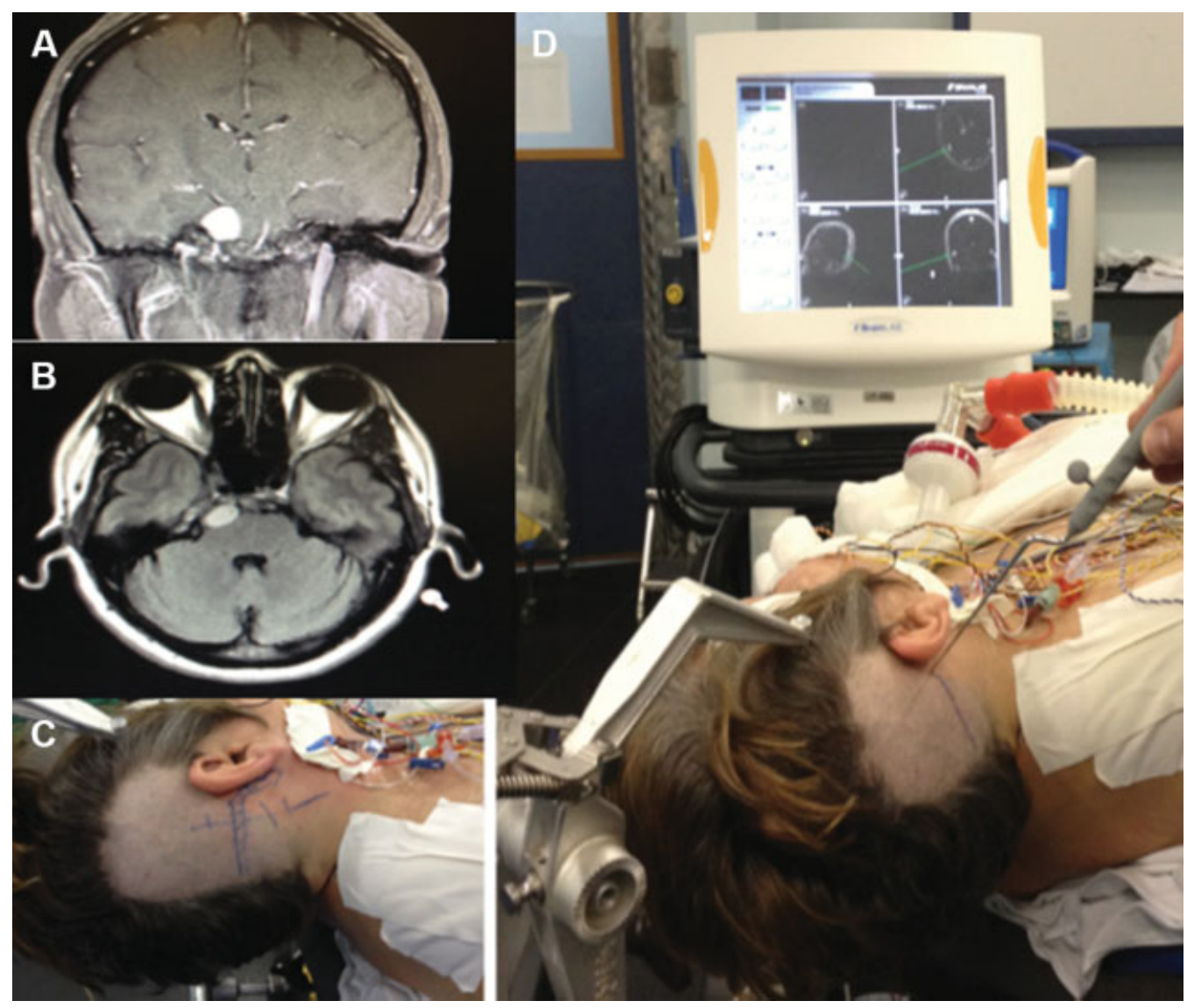

Fig. 5 Patient with a small petroclival meningioma in the upper clivus that was resected by the retrosigmoid approach. Coronal (A) and axial (B) gadolinium-enhanced MRI scans. Incision site (C) and neuronavigation showing the junction position of the transverse and sigmoid sinuses (D).

neurological function. ${ }^{25-27}$ Nicolato et $\mathrm{al}^{26}$, in a series of posterior fossa meningiomas treated with gamma knife radiosurgery, reported that the only factor to influence the efficacy of radiosurgery to a significant extent was the biological nature of the meningioma (WHO grades 2 and 3). In 1998, Subach et $\mathrm{al}^{28}$ reported good outcomes in 62 cases of petroclival meningioma, with $\mathrm{CN}$ deficits occurring in $8 \%$ of patients. Iwai et $\mathrm{al}^{27}$ also reported good results in a series of seven patients with large petroclival and cavernous sinus meningiomas treated with gamma knife radiosurgery in a two-stage procedure. Xu et $\mathrm{al}^{29}$ recommended that radiosurgery should be considered for petroclival meningiomas on a case-by-case basis, taking into account patient age, size, and location of residual tumor, and pathologic features. In 2010, Flannery et $\mathrm{al}^{30}$ published their 21-year experience with gamma knife treatment of petroclival meningiomas. The authors were able to avoid initial or additional resection in $98 \%$ of patients with a low risk of radiation-related adverse effects and believed that radiosurgery should be considered a first-line option for patients with small, symptomatic petroclival meningiomas. Conversely, in their study, overall 5- and 10-year progressionfree survival rates were $91 \%$ and $86 \%$, respectively.

Long-term reports of radiosurgical results have shown actuarial progression-free survival rates in skull base meningiomas of $97.2 \%$ at 10 years. Kreil et $\mathrm{al}^{25}$ reported 44 petroclival meningiomas from 200 patients with benign skull base meningiomas in 5 to 12 years of follow-up; 99 patients received gamma knife radiosurgery after microsurgical resection, and 101 patients underwent upfront SRS. The median tumor volume was $6.5 \mathrm{~cm}^{3}$. Five patients needed repeated microsurgical resection following SRS (2.5\%). Hence, for particular cases of small sphenopetroclival meningiomas with cavernous sinus symptoms (CN III, IV, or VI paresis), we consider radiosurgery the initial treatment of choice. However, further studies reporting 20 -year results or even longer post-radiosurgery observation are necessary. This is important not just for estimating the long-term outcomes of radiosurgical treatment, but also to evaluate surgical outcomes in patients in whom radiosurgery was unable to control tumor growth. Conversely, we believe that surgery should be the primary treatment for petroclival meningiomas in patients with good clinical condition. Besides that, in the presence of neuropathic pain refractory to medical therapy or progressive visual loss due to compression of the optic apparatus, we have performed surgical decompression prior to radiosurgery.

The choice of surgical approach is typically based on the location, extent of tumor involvement, and experience of the surgeon. The involvement of venous structures must be taken into account, such as the vein of Labbé, the superior 


\begin{tabular}{|c|c|c|c|c|c|c|c|c|}
\hline 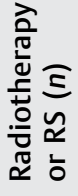 & - & 1 & 1 & - & - & 1 & - & - \\
\hline 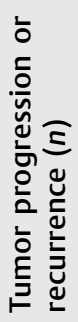 & $\stackrel{\infty}{=}$ & $\frac{\varphi}{r}$ & $\frac{N}{O}$ & $\stackrel{\simeq}{=}$ & $\lesssim$ & $\bar{c}$ & $\overline{0}$ & $\bar{o}$ \\
\hline 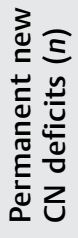 & $\frac{\infty}{\sim}$ & $\stackrel{\varphi}{r}$ & $\frac{N}{N}$ & $\stackrel{N}{=}$ & $\bar{\sigma}$ & $\lesssim$ & $\bar{\sigma}$ & $\bar{\sigma}$ \\
\hline 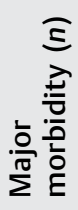 & $\frac{\infty}{0}$ & $\frac{\varphi}{v}$ & $\frac{N}{N}$ & $\stackrel{N}{=}$ & $\bar{\sigma}$ & 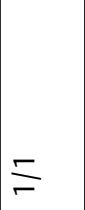 & $\overline{0}$ & $\overline{0}$ \\
\hline 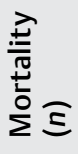 & 0 & 0 & - & - & 0 & 0 & 0 & 0 \\
\hline 结 & 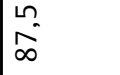 & $\hat{\theta}$ & ㅇํ & 유 & 0 & 0 & 0 & 0 \\
\hline 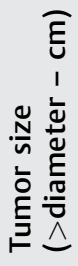 & 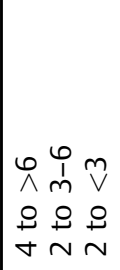 & $\begin{array}{ll}0 & 0 \\
1 & 0 \\
m & 0 \\
0 & 0 \\
\forall & \sim\end{array}$ & 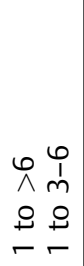 & $\begin{array}{ll}1 & 0 \\
1 & 0 \\
m & 1 \\
0 & 0 \\
1 & 0 \\
1 & 1\end{array}$ & $\begin{array}{l}\tilde{v} \\
0 \\
-\end{array}$ & $\begin{array}{l}\tilde{v} \\
\stackrel{v}{q} \\
r\end{array}$ & $\begin{array}{l}0 \\
1 \\
m \\
0 \\
1 \\
-\end{array}$ & $\begin{array}{l}0 \\
\hat{\imath} \\
\stackrel{2}{-}\end{array}$ \\
\hline$=$ & $\infty$ & 6 & $\sim$ & $\sim$ & - & - & - & - \\
\hline 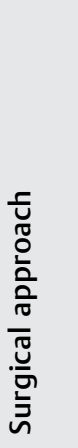 & 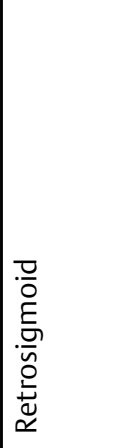 & 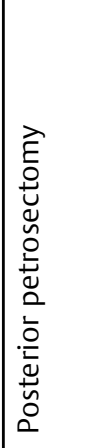 & 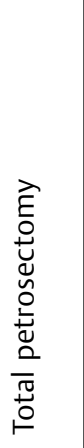 & 온 & 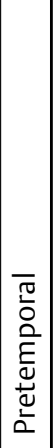 & 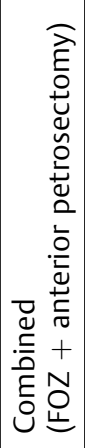 & 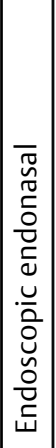 & \begin{tabular}{|l} 
\\
\\
$\stackrel{n}{s}$
\end{tabular} \\
\hline
\end{tabular}

Table 4 Surgically induced deficits and improved previous deficits and correlation with Simpson grade of resection

\begin{tabular}{|l|l|l|l|}
\hline $\begin{array}{l}\text { Simpson } \\
\text { grade }\end{array}$ & $\begin{array}{l}\text { New postoperative } \\
\text { or worsened } \\
\text { CN deficit }\end{array}$ & $\begin{array}{c}\text { New deficit } \\
6 \text { months } \\
\text { later }\end{array}$ & $\begin{array}{l}\text { Improvement of } \\
\text { previous deficit }\end{array}$ \\
\hline I (0) & - & - & - \\
\hline II (11) & 9 & 5 & 3 \\
\hline III (7) & 2 & 1 & 0 \\
\hline IV (4) & 1 & 0 & 1 \\
\hline $\mathrm{V}(0)$ & - & - & - \\
\hline
\end{tabular}

Abbreviation: $\mathrm{CN}$, cranial nerve.

petrosal and transverse sinuses, and the petrosal vein. This is important especially for the petrosal approaches..$^{20}$ For tumors extending into the middle fossa, Samii et al proposed the suprameatal approach, ${ }^{18}$ which includes drilling of the temporal bone above the internal auditory meatus to reach the middle fossa. However, Chen et $\mathrm{al}^{12}$ postulated that the exposure of this part of the tumor would be inadequate, because of the small angle for tumor resection, and the risk of postoperative neurological deficits would be more important than achieving GTR with tumor extension into the cavernous sinus. They considered that tumors invading the cavernous sinus could not be removed completely.

Almefty et al reported a series of 64 patients and found that complete resection (Grade I or II) of petroclival meningiomas was possible in $76.4 \%$ of cases. ${ }^{15}$ The authors suggested that, when circumstances prevent complete resection, residual tumors can be managed by watchful waiting until there is evidence of progression, at which time a new intervention could be planned. Regarding approaches, we believe that the suboccipital retrosigmoid approach for tumors without ex-

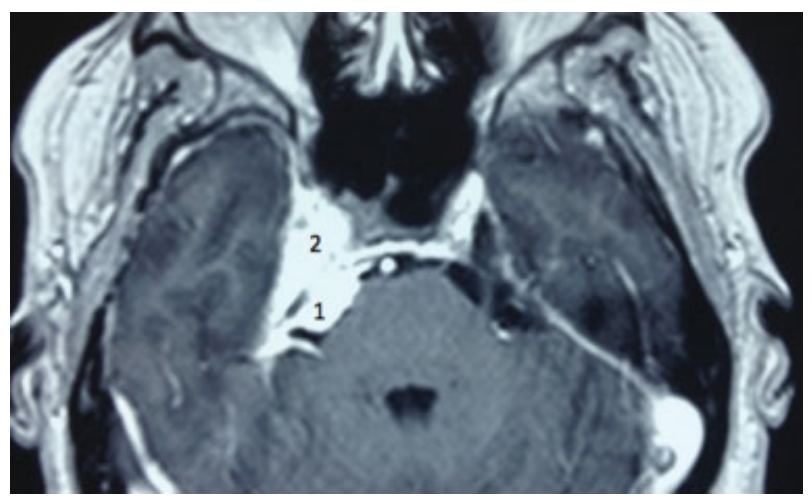

Fig. 6 Axial gadolinium-enhanced T1-weighted MRI showing a sphenopetroclival meningioma. A 48-year-old patient presented refractory trigeminal neuropathic pain for 4 months. After partial resection of the petroclival portion of the tumor, her pain improved, and she remained with hypoesthesia. After 2 years, the tumor grew, and she was treated with radiosurgery, without development of trigeminal neuropathy. 1 . Clival portion and 2. cavernous portion. MRI, magnetic resonance imaging. 


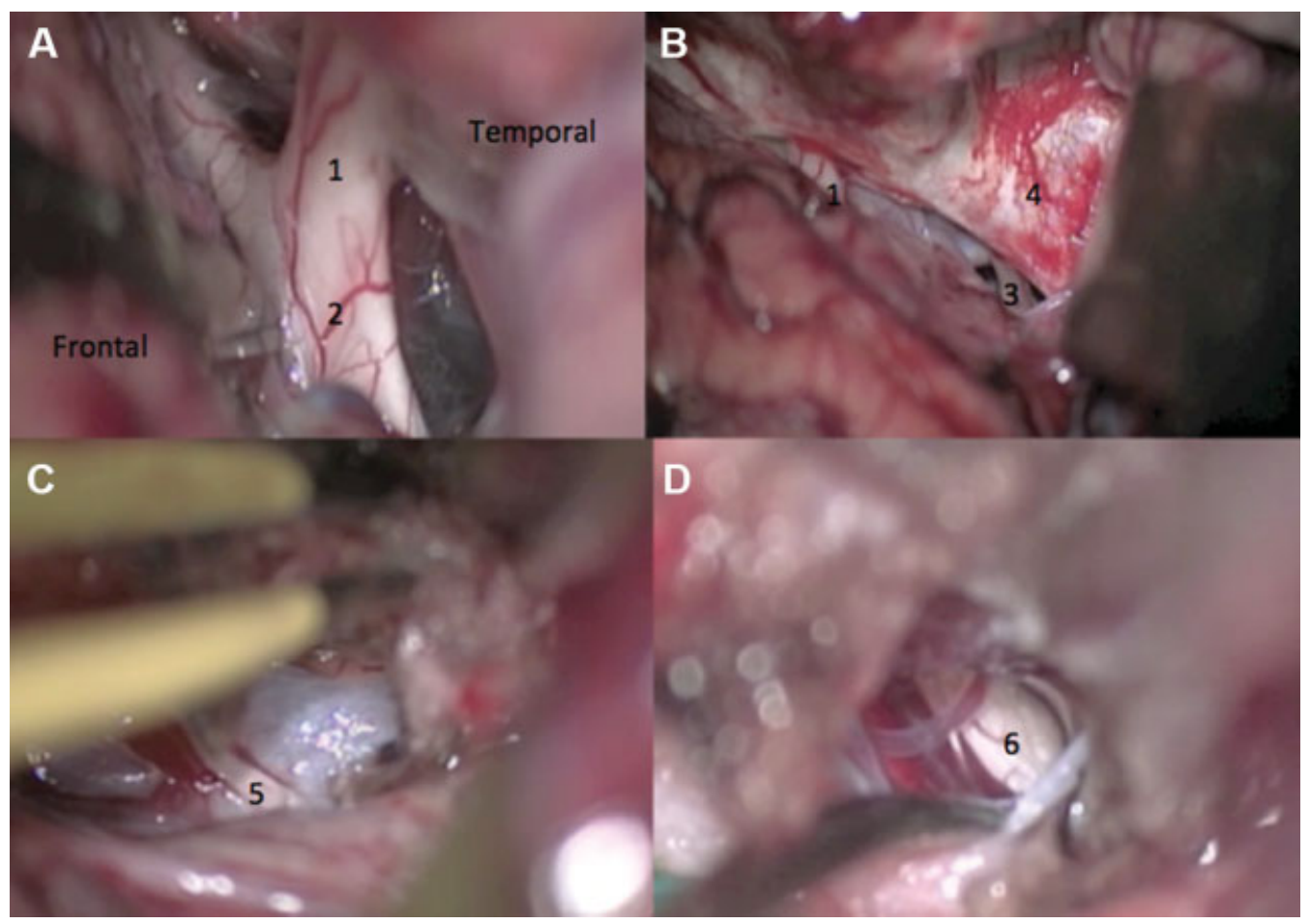

Fig. 7 Intraoperative view of a pretemporal approach for sphenopetroclival meningioma resection causing neuropathic pain in the right trigeminal nerve. (A) Wide dissection of the Sylvian fissure. (B) Temporal lobe was retracted posteriorly to expose the crural and ambient cisterns. (C) Coagulation and incision of the free edge of the tentorium after trochlear nerve dissection. (D) Resection of the posterior fossa tumor component with decompression of the trigeminal nerve. 1 . Optic nerve; 2 . optic chiasm; 3 . oculomotor nerve; 4 . wall of the cavernous sinus; 5. trochlear nerve; and 6. trigeminal nerve.

tension into the middle fossa is usually sufficient. With the aid of long microsurgical instruments, ultrasonic aspirators and a surgical microscope with great mobilization capacity for changing the angle of view of the surgical field, the retrosigmoid approach provides satisfactory access to the tumor component, although from a different angle of view compared with petrosal approaches.

This does not mean that we consider the petrosal approach an aggressive approach, as did Bricolo et al by considering the retrosigmoid approach, subtemporal approach and their combination "less-aggressive" skull base approaches. ${ }^{2}$ However, the latter are becoming more common in the surgical removal of petroclival meningiomas. ${ }^{2,26}$ Bricolo et $\mathrm{al}^{2}$ used the retrosigmoid approach alone in $65 \%$ of 110 consecutive patients. Bambakidis et $\mathrm{al}^{9}$ reviewed 46 patients who underwent surgical treatment of petroclival meningiomas. The rate of GTR was $43 \%$. Cases in which a retrosigmoid resection was performed showed no reduction in tumor progression and recurrence rates. They found that the mean length of stay for patients undergoing a less-aggressive approach was 1 week less than that for patients undergoing an aggressive approach (17 vs 23 days). Goel ${ }^{6}$ also found no association between the surgical approaches and the extent of resection. - Table $\mathbf{5}$ shows the comparative results with major surgical series of petroclival meningiomas. ${ }^{4,31-48}$

Tumors with extension into the middle fossa, more precisely extending above the tentorium notch, were ap- proached through an access to the lateral skull base. Once the tentorium is completely transected, petrosal approaches provide a better view of the entire tumor extension in a single procedure in cases of real midline retroclival tumors, with supratentorial and middle fossa invasion.

Although endoscopic endonasal approaches are becoming increasingly applied, they were used in only one case in which the patient had rhinorrhea due to erosion of the sphenoid sinus by a small sphenopetroclival tumor, which was later referred for radiosurgery. The endoscopic approach for petroclival endonasal meningiomas would theoretically have the advantage of dealing with the CNs at a distance from the surgeon, i.e., the rear surface of the tumor. Moreover, except for midclival meningiomas, the lateral location and displacement of both abducens nerves to the same side would likely increase the risk of $\mathrm{CN}$ VI palsy. In addition, the deep surgical field and increased risk of CSF fistula are also disadvantages compared with the approaches commonly used for resection of this type of tumor.

Tumor progression or recurrence was observed in three of 14 patients (21.4\%) followed for $>6$ months, and in four ( $18 \%)$ of the total 22 patients included in the study; all of them had undergone subtotal resection. The small number of patients and relatively short follow-up in our series prevented us from performing additional analyses. Nevertheless, none of the patients with GTR had recurrence. 
Table 5 Comparative results with major surgical series of petroclival meningiomas

\begin{tabular}{|c|c|c|c|c|c|}
\hline Reference & $N$ & $\begin{array}{l}\text { Gross-total } \\
\text { resection }^{\mathrm{a}}(\%)\end{array}$ & $\begin{array}{l}\text { Mortality } \\
(\%)\end{array}$ & $\begin{array}{l}\text { Major } \\
\text { morbidity (\%) }\end{array}$ & $\begin{array}{l}\text { New cranial } \\
\text { nerve deficits (\%) }\end{array}$ \\
\hline Yasargil et al. $^{1}$ & 20 & 35 & 10 & 26 & 50 \\
\hline Mayberg and Simon 31 & 35 & 26 & 9 & 34 & 54 \\
\hline Nishimura et al. ${ }^{32}$ & 24 & 63 & 8 & 33 & 91 \\
\hline Tatagiba et al. ${ }^{4}$ & 54 & 70 & 2 & 24 & 37 \\
\hline Bricolo et al. ${ }^{2}$ & 33 & 79 & 9 & 39 & 76 \\
\hline Spetzler et al. ${ }^{33}$ & 18 & 78 & 0 & 11 & 39 \\
\hline Kawase et al. ${ }^{3}$ & 42 & 76 & 0 & 12 & 36 \\
\hline Coudwell et al. ${ }^{5}$ & 109 & 69 & 3.7 & 15 & 33 \\
\hline Zentner et al. ${ }^{34}$ & 19 & 68 & 5 & 11 & 34 \\
\hline Goel $^{6}$ & 24 & 67 & 0 & 29 & 29 \\
\hline Abdel Aziz et al. ${ }^{35}$ & 35 & 37 & 0 & 9 & 31 \\
\hline Little et al. ${ }^{7}$ & 137 & 40 & 0.7 & 26 & 22 \\
\hline Park et al. ${ }^{36}$ & 49 & 20 & 2 & 28.6 & 28.6 \\
\hline Mathiesen et al. ${ }^{37}$ & 29 & 48 & 0 & 7 & 21 \\
\hline Natarajan et al. ${ }^{8}$ & 150 & 32 & 0 & 22 & 20.3 \\
\hline Bambakidis et al. ${ }^{9}$ & 46 & 43 & 0 & 41 & 30 \\
\hline Ramina et al. $^{10}$ & 67 & 55 & 3 & 12 & 33 \\
\hline Tahara et al. ${ }^{38}$ & 15 & 50 & 13 & 20 & 50 \\
\hline Seifert $^{11}$ & 148 & 37 & 0 & 31 & 22 \\
\hline Li et al. ${ }^{39}$ & 57 & 58 & 2 & 42 & 67 \\
\hline Yang et al. ${ }^{40}$ & 41 & 61 & 0 & 66 & 8 \\
\hline Yamakami et al. ${ }^{41}$ & 32 & 59 & 6 & 28 & 22 \\
\hline Watanabe et al. ${ }^{42}$ & 26 & 42 & 0 & 15 & 15 \\
\hline Shi et al. ${ }^{43}$ & 14 & 86 & 0 & 43 & 43 \\
\hline Chen et al. ${ }^{12}$ & 82 & 56 & 5 & 44 & 39 \\
\hline Nanda et al. ${ }^{13}$ & 50 & 28 & 6 & 44 & 32 \\
\hline Kusumi et al. ${ }^{44}$ & 23 & 47 & 0 & 22 & 43 \\
\hline Matsui $^{45}$ & 15 & 67 & 0 & 27 & 27 \\
\hline Li et al. ${ }^{14}$ & 259 & 52.5 & 1.2 & 54 & 54 \\
\hline Almefty et al. ${ }^{15}$ & 64 & 64 & 8 & 25 & 39 \\
\hline Morisako et al. ${ }^{46}$ & $60(24 / 36)^{b}$ & EOR $96.1 / 92.7^{c}$ & 1.7 & 25 & 46.7 \\
\hline da Silva \& de Freitas ${ }^{47}$ & $8 / 16$ & 87.5 & 0 & 37.5 & 37.5 \\
\hline Tatagiba et al. ${ }^{4}$ & $29 / 87$ & 66 & 0 & 24 & 34 \\
\hline Zhou et al. $^{48}$ & 24 & 33.3 & 0 & 20.8 & 37.5 \\
\hline Isolan et al., 2015 & 22 & 50 & 4.5 & 27.3 & 13.6 \\
\hline
\end{tabular}

Data in bold correspond to the current study.

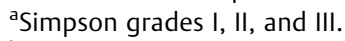

b24 cases in the early group (1990-1999) and 36 cases in the late group (2000-2009).

${ }^{c}$ Extent of resection (EOR) was calculated as follows: $E O R(\%)=($ preoperative tumor volume - postoperative tumor volume)/preoperative tumor volume $\times 100$. 


\section{Conclusions}

Resection of petroclival meningiomas remains challenging. Early in the series, petrosal approaches were used primarily, but, over the course of the learning curve, the retrosigmoid approach was considered generally sufficient for most patients, without affecting the degree of tumor resection. In asymptomatic cases extending into the cavernous sinus, follow-up was performed, and radiosurgery in case of tumor growth. The petrosal approaches were reserved for patients with tumor extension into the middle fossa.

\section{Conflicts of Interest}

None.

\section{Financial Disclosure}

The authors have no financial relationships relevant to this article to disclose.

\section{References}

1 Yasargil MG, Mortara RW, Curcic M. Meningiomas of basal posterior cranial fossa. Adv Tech Stand Neurosurg 1980:3-115. doi: 10.1007/978-3-7091-7051-9_1

2 Bricolo AP, Turazzi S, Talacchi A, Cristofori L. Microsurgical removal of petroclival meningiomas: a report of 33 patients. Neurosurgery 1992;31(05):813-828, discussion 828

3 Kawase T, Shiobara R, Toya S. Middle fossa transpetrosal-transtentorial approaches for petroclival meningiomas. Selective pyramid resection and radicality. Acta Neurochir (Wien) 1994;129(3-4):113-120

4 Tatagiba M, Samii M, Matthies C, Vorkapic P. Management of petroclival meningiomas: a critical analysis of surgical treatment. Acta Neurochir Suppl (Wien) 1996;65:92-94

5 Couldwell WT, Fukushima T, Giannotta SL, Weiss MH. Petroclival meningiomas: surgical experience in 109 cases. J Neurosurg 1996;84(01):20-28

6 Goel A. Extended lateral subtemporal approach for petroclival meningiomas: report of experience with 24 cases. Br J Neurosurg 1999;13(03):270-275

7 Little KM, Friedman AH, Sampson JH, Wanibuchi M, Fukushima T. Surgical management of petroclival meningiomas: defining resection goals based on risk of neurological morbidity and tumor recurrence rates in 137 patients. Neurosurgery 2005;56(03): 546-559, discussion 546-559

8 Natarajan SK, Sekhar LN, Schessel D, Morita A. Petroclival meningiomas: multimodality treatment and outcomes at long-term follow-up. Neurosurgery 2007;60(06):965-979, discussion 979-981

9 Bambakidis NC, Kakarla UK, Kim LJ, et al. Evolution of surgical approaches in the treatment of petroclival meningiomas: a retrospective review. Neurosurgery 2007;61(05, Suppl 2):202-209, discussion 209-211

10 Ramina R, Fernandes YB, Coelho Neto M. Petroclival meningiomas: diagnosis, treatment, and results. In: Ramina R, Tatagiba M, eds. Samii's Essentials in Neurosurgery. Berlin: Springer Berlin Heidelberg; 2008:121-135

11 Seifert V. Clinical management of petroclival meningiomas and the eternal quest for preservation of quality of life: personal experiences over a period of 20 years. Acta Neurochir (Wien) 2010;152(07):1099-1116

12 Chen LF, Yu XG, Bu B, Xu BN, Zhou DB. The retrosigmoid approach to petroclival meningioma surgery. J Clin Neurosci $2011 ; 18(12)$ : 1656-1661
13 Nanda A, Javalkar V, Banerjee AD. Petroclival meningiomas: study on outcomes, complications and recurrence rates. J Neurosurg 2011;114(05):1268-1277

14 Li D, Hao SY, Wang L, et al. Surgical management and outcomes of petroclival meningiomas: a single-center case series of 259 patients. Acta Neurochir (Wien) 2013;155(08):1367-1383

15 Almefty R, Dunn IF, Pravdenkova S, Abolfotoh M, Al-Mefty O. True petroclival meningiomas: results of surgical management. J Neurosurg 2014;120(01):40-51

16 Castellano F, Ruggiero G. Meningiomas of the posterior fossa. Acta Radiol Suppl 1953;104:1-177

17 Samii M, Tatagiba M. Experience with 36 surgical cases of petroclival meningiomas. Acta Neurochir (Wien) 1992;118(1-2):27-32

18 Samii M, Tatagiba M, Carvalho GA. Retrosigmoid intradural suprameatal approach to Meckel's cave and the middle fossa: surgical technique and outcome. J Neurosurg 2000;92(02):235-241

19 Simpson D. The recurrence of intracranial meningiomas after surgical treatment. J Neurol Neurosurg Psychiatry 1957;20(01): 22-39

20 Hafez A, Nader R, Al-Mefty O. Preservation of the superior petrosal sinus during the petrosal approach. J Neurosurg 2011; 114(05):1294-1298

21 Wayhs SY, Lepski GA, Frighetto L, Isolan GR. Petroclival meningiomas: Remaining controversies in light of minimally invasive approaches. Clin Neurol Neurosurg 2017;152:68-75

22 Van Havenbergh T, Carvalho G, Tatagiba M, Plets C, Samii M. Natural history of petroclival meningiomas. Neurosurgery 2003; 52(01):55-62, discussion 62-64

23 Jung HW, Yoo H, Paek SH, Choi KS. Long-term outcome and growth rate of subtotally resected petroclival meningiomas: experience with 38 cases. Neurosurgery 2000;46(03):567-574, discussion 574-575

24 Ramina R, Neto MC, Fernandes YB, Silva EB, Mattei TA, Aguiar PH. Surgical removal of small petroclival meningiomas. Acta Neurochir (Wien) 2008;150(05):431-438, discussion 438-439

25 Kreil W, Luggin J, Fuchs I, Weigl V, Eustacchio S, Papaefthymiou G. Long term experience of gamma knife radiosurgery for benign skull base meningiomas. J Neurol Neurosurg Psychiatry 2005;76 (10):1425-1430

26 Nicolato A, Foroni R, Pellegrino M, et al. Gamma knife radiosurgery in meningiomas of the posterior fossa. Experience with 62 treated lesions. Minim Invasive Neurosurg 2001;44(04): 211-217

27 Iwai Y, Yamanaka K, Nakajima H. Two-staged gamma knife radiosurgery for the treatment of large petroclival and cavernous sinus meningiomas. Surg Neurol 2001;56(05):308-314

28 Subach BR, Lunsford LD, Kondziolka D, Maitz AH, Flickinger JC. Management of petroclival meningiomas by stereotactic radiosurgery. Neurosurgery 1998;42(03):437-443, discussion 443445

29 Xu F, Karampelas I, Megerian CA, Selman WR, Bambakidis NC. Petroclival meningiomas: an update on surgical approaches, decision making, and treatment results. Neurosurg Focus 2013; 35(06):E11

30 Flannery TJ, Kano $\mathrm{H}$, Lunsford LD, et al. Long-term control of petroclival meningiomas through radiosurgery. J Neurosurg 2010;112(05):957-964

31 Mayberg MR, Symon L. Meningiomas of the clivus and apical petrous bone. Report of 35 cases. J Neurosurg 1986;65(02): 160-167

32 Nishimura S, Hakuba A, Jang BJ, Inoue Y. Clivus and apicopetroclivus meningiomas-report of 24 cases. Neurol Med Chir (Tokyo) 1989;29(11):1004-1011

33 Spetzler RF, Daspit CP, Pappas CT. The combined supra- and infratentorial approach for lesions of the petrous and clival regions: experience with 46 cases. J Neurosurg 1992;76(04): 588-599 
34 Zentner J, Meyer B, Vieweg U, Herberhold C, Schramm J. Petroclival meningiomas: is radical resection always the best option? J Neurol Neurosurg Psychiatry 1997;62(04):341-345

35 Abdel Aziz KM, Sanan A, van Loveren HR, Tew JM Jr, Keller JT, Pensak ML. Petroclival meningiomas: predictive parameters for transpetrosal approaches. Neurosurgery 2000;47(01):139-150, discussion 150-152

36 Park CK, Jung HW, Kim JE, Paek SH, Kim DG. The selection of the optimal therapeutic strategy for petroclival meningiomas. Surg Neurol 2006;66(02):160-165, discussion 165-166

37 Mathiesen T, Gerlich A, Kihlström L, Svensson M, Bagger-Sjöbäck D. Effects of using combined transpetrosal surgical approaches to treat petroclival meningiomas. Neurosurgery 2007;60(06): 982-991, discussion 991-992

38 Tahara A, de Santana PA Jr, Calfat Maldaun MV, et al. Petroclival meningiomas: surgical management and common complications. J Clin Neurosci 2009;16(05):655-659

39 Li PL, Mao Y, Zhu W, Zhao NQ Zhao Y, Chen L. Surgical strategies for petroclival meningioma in 57 patients. Chin Med J (Engl) 2010; 123(20):2865-2873

40 Yang J, Fang T, Ma S, et al. Large and giant petroclival meningiomas: therapeutic strategy and the choice of microsurgical approaches - report of the experience with 41 cases. $\mathrm{Br} \mathrm{J}$ Neurosurg 2011;25(01):78-85

41 Yamakami I, Higuchi Y, Horiguchi K, Saeki N. Treatment policy for petroclival meningioma based on tumor size: aiming radical removal in small tumors for obtaining cure without morbidity. Neurosurg Rev 2011;34(03):327-334, discussion 334-335

42 Watanabe T, Katayama Y, Fukushima T, Kawamata T. Lateral supracerebellar transtentorial approach for petroclival meningiomas: operative technique and outcome. J Neurosurg 2011;115 (01):49-54

43 Shi W, Shi JL, Xu QW, Che XM, Ju SQ Chen J. Temporal base intradural transpetrosal approach to the petoclival region: an appraisal of anatomy, operative technique and clinical experience. Br J Neurosurg 2011;25(06):714-722

44 Kusumi M, Fukushima T, Mehta AI, et al. Tentorial detachment technique in the combined petrosal approach for petroclival meningiomas. J Neurosurg 2012;116(03):566-573

45 Matsui T. Therapeutic strategy and long-term outcome of meningiomas located in the posterior cranial fossa. Neurol Med Chir (Tokyo) 2012;52(10):704-713

46 Morisako H, GotoT, Ohata K. Petroclival meningiomas resected via a combined transpetrosal approach: surgical outcomes in 60 cases and a new scoring system for clinical evaluation. J Neurosurg 2015;122(02):373-380

47 da Silva CE, de Freitas PE. Large and giant skull base meningiomas: the role of radical surgical removal. Surg Neurol Int 2015;6:113

48 Zhou QJ, Liu B, Geng DJ, et al. Microsurgery with or without neuroendoscopy in petroclival meningiomas. Turk Neurosurg 2015;25(02):231-238 